\title{
Catalytic conversion of furanic compounds over Ga-modified ZSM-5 zeolites as a route to biomass-derived aromatics
}

Citation for published version (APA):

Uslamin, E. A., Kosinov, N. A., Pidko, E. A., \& Hensen, E. J. M. (2018). Catalytic conversion of furanic compounds over Ga-modified ZSM-5 zeolites as a route to biomass-derived aromatics. Green Chemistry, 20(16), 3818-3827. https://doi.org/10.1039/C8GC01528G

DOI:

10.1039/C8GC01528G

Document status and date:

Published: 18/07/2018

\section{Document Version:}

Author's version before peer-review

\section{Please check the document version of this publication:}

- A submitted manuscript is the version of the article upon submission and before peer-review. There can be important differences between the submitted version and the official published version of record. People interested in the research are advised to contact the author for the final version of the publication, or visit the $\mathrm{DOI}$ to the publisher's website.

- The final author version and the galley proof are versions of the publication after peer review.

- The final published version features the final layout of the paper including the volume, issue and page numbers.

Link to publication

\section{General rights}

Copyright and moral rights for the publications made accessible in the public portal are retained by the authors and/or other copyright owners and it is a condition of accessing publications that users recognise and abide by the legal requirements associated with these rights.

- Users may download and print one copy of any publication from the public portal for the purpose of private study or research.

- You may not further distribute the material or use it for any profit-making activity or commercial gain

- You may freely distribute the URL identifying the publication in the public portal.

If the publication is distributed under the terms of Article 25fa of the Dutch Copyright Act, indicated by the "Taverne" license above, please follow below link for the End User Agreement:

www.tue.nl/taverne

Take down policy

If you believe that this document breaches copyright please contact us at:

openaccess@tue.nl

providing details and we will investigate your claim. 


\section{Catalytic conversion of furanic compounds over Ga-modified ZSM-5 zeolites as a route to biomass-derived aromatics}

Evgeny A. Uslamin, ${ }^{1}$ Nikolay $\operatorname{Kosinov}^{1}$, Evgeny A. Pidko, ${ }^{1,+}, *$ and Emiel J.M. Hensen ${ }^{1, *}$

${ }^{1}$ Schuit Institute of Catalysis, Laboratory of Inorganic Materials Chemistry, Eindhoven University of Technology, PO Box 513, 5600 MB Eindhoven, The Netherlands

${ }^{\dagger}$ Current address: Inorganic Systems Engineering group, Department of Chemical Engineering, Delft University of Technology, Van der Maasweg 9, 2629 HZ, Delft, The Netherlands

Corresponding author: E.J.M.H. (e.j.m.hensen@tue.nl); E.A.P. (e.a.pidko@tudelft.nl) 


\begin{abstract}
Herein we report a mechanistic study of aromatization of furanics, as model compounds for cellulosic biomass, over (Ga)HZSM-5 catalysts. Applying combined gas chromatography and mass-spectrometry product analysis we were able to analyse conversion and selectivity reaction profiles with high temporal resolution. The thorough analysis of the product distribution allowed us to resolve the deoxygenation pathways of the furan molecules. We found that depending on the methyl substitution oxygen is removed either as water or $\mathrm{CO}_{x}$, effecting the carbon efficiency of the process. While unsubstituted furan undergoes decarbonylation to form $\mathrm{CO}_{x}$, methylated furans are deoxygenated by dehydration, resulting in a much higher carbon-efficiency. Furthermore, using in-situ IR spectroscopy, we found that promotion of HZMS-5 with Ga in addition to enhanced aromatic selectivity influences the deactivation pathway leading to the preferential formation of proton-deficient polycyclic aromatic compounds.
\end{abstract}

Keywords: aromatic: biomass; furan; HZSM-5; aromatics; gallium 


\section{Introduction}

Driven by societal and economic concerns related to the use of fossil resources, there is growing attention for their replacement by renewable carbon sources. ${ }^{12}$ The conversion of whole lignocellulosic biomass or its constituents - cellulose, hemi-cellulose ${ }^{34}$, and lignin ${ }^{5}$ - into sustainable fuels and chemicals is expected to become increasingly important for the chemical industry. Common approaches involve upgrading of oils derived from biomass for instance by pyrolysis ${ }^{6}$ or of synthesis gas obtained from biomass gasification. ${ }^{7}$ Another promising strategy is to convert the complex molecules contained in biomass into platform chemicals such as ethanol, glycerol or furanic compounds from which a wide range of chemical products can be obtained. ${ }^{89}$ Aromatics represent another class of platform chemicals in this context, which can also be considered as drop-in chemicals as they are currently already used at a very large scale in the chemical industry. BTX (benzene, toluene and xylenes) are currently almost exclusively derived from crude oil. An alternative route to BTX is by chemical conversion of raw lignocellulosic biomass or biomass-derived platform molecules. ${ }^{1011}$

Catalytic fast pyrolysis (CFP) is a promising way for the conversion of biomass into aromatics. CFP involves two main steps: oxygen-free pyrolysis of raw biomass followed by catalytic conversion of the resulting vapours over an acidic catalyst, usually a microporous zeolite. ${ }^{3,8}$ The highest BTX selectivity was achieved with medium-pore zeolites such as ZSM-5 and ZSM-11, providing ca. 35\% and 25\% overall selectivity to aromatics, respectively, in CFP of glucose. ${ }^{12}$ On the other hand, some studies on the CFP of woody biomass claim that aromatics are predominantly derived from the lignin part of the feedstock, while the more reactive carbohydrate fraction lead to coke and carbon oxides. ${ }^{13}$

Optimization of the CFP process is hampered by the significant complexity of the high-temperature reaction chemistry of the heterogeneous over-functionalized biomass feedstock. To better understand the molecular transformations underlying CFP, mechanistic studies with model compounds are useful. Recently, it has for instance been shown that furanic compounds are representative for the main components of pyrolysis mixtures. ${ }^{14,15}$ Besides, furans represent a class of biomass-derived platform molecules that can be directly obtained from the carbohydrate fraction of lignocellulosic biomass. ${ }^{16,17}$

Furan can be aromatized on zeolite catalysts. A typical product mixture contains carbon oxides, light hydrocarbons, light and polycyclic aromatics and coke. ${ }^{3}$ The conversion and product distribution depend strongly on the experimental conditions. The yield of aromatics, mostly comprised of BTX, varies as a function of the acidity and pore dimensions of the zeolite catalyst. ${ }^{18}$ It is well known that the MFI topology comprised of 10-membered ring pores favours the formation of small aromatic molecules and thereby limits deactivation. ${ }^{19,2021}$ The overall aromatics selectivity for furan aromatization over HZSM-5 was about $30 \%$ at $600{ }^{\circ} \mathrm{C}$ at a WHSV (weight hourly space velocity, $h^{-1}$; defined as flow rate of feed in 
$g / h$ divided by the weight of the catalyst $g$ ) of $10 \mathrm{~h}^{-1}$ and a conversion of $50 \%{ }^{2223}$ The BTX selectivity was lower than $15 \%$. The BTX selectivity is usually higher at lower temperature. For instance, at $450{ }^{\circ} \mathrm{C}$ it reached $20 \%{ }^{1424}$ The product distribution also strongly varies with the contact time. ${ }^{25}$

Despite the recognized potential of CFP, there is a lack of detailed understanding about the reaction mechanism, which hampers the design of better catalysts with a higher BTX selectivity and a lower rate of coke formation. A specific challenge is rapid catalyst deactivation due to deposition of carbonaceous deposits in the zeolite micropores. As such, most studies mainly report cumulative conversions and selectivities. Aromatization of furan is proposed to include deoxygenation through either dehydration or decarbonylation followed by aromatization of olefinic or acetylenic reaction intermediates. Decarbonylation results in allene or methylacetylene as reaction intermediates. ${ }^{26}$ Another extensively discussed mechanism is the Diels-Alder cycloaddition pathway. ${ }^{14,22}$ It involves the cycloaddition of either another furan or another unsaturated hydrocarbon to form benzofuran or substituted aromatics, respectively. Such intermediates would undergo a cascade of carbocation-based transformations over the Brønsted acid sites (BAS) in zeolite micropores including isomerization and alkylation/dealkylation reactions.

Modification of zeolites is a way to increase the aromatics and BTX yield of the CFP process. ${ }^{27,28}$ The group of Huber was the first to use Ga-modified zeolites for this purpose. ${ }^{23}$ Introduction of Ga in HZSM5 by ion exchange allows increasing the overall aromatics selectivity from $31 \%$ to $44 \%$ at $600^{\circ} \mathrm{C}$ and a WHSV of $10.4 \mathrm{~h}^{-1}$. Originally, the promoting role of Ga was ascribed predominantly to the decreased Brønsted acidity of the ion-exchanged zeolites. However, it was also speculated that intra-zeolite Ga species are also important for promoting decarbonylation and olefin aromatization reactions.

In this work we investigated the mechanism of the aromatization of furanic compounds on zeolites. Using fast quantitative online GC analysis of the reactor effluent we investigate the effect of the zeolite catalyst properties and the structure of substrate on the reaction performance. By carrying out the catalytic reactions at relatively low space velocity (WHSV $\sim 0.4 \mathrm{~h}^{-1}$ ) in combination with fast qualitative and quantitative analysis methods we can accurately determine the product composition as a function of time on stream. We combine this approach with IR spectroscopy and mass spectrometry (MS) measurements of the reaction in a temperature-programmed reaction (TPR) mode to investigate adsorption and thermal decomposition of model furanic compounds such as furan, 2-methylfuran (2-MF) and 2,5-dimethylfuran (2,5-dMF) over Ga-modified HZSM-5 zeolites. The utilization of well-defined catalysts and their thorough characterization provide important information on the role of Brønsted and Lewis acidity on the reaction outcome. We show that the aromatization of furanics is a cascade processes including mostly isomerization, disproportionation and cracking reactions. IR spectroscopy results evidence the crucial role 
of Ga for the formation of aromatic products and highlight the importance of the nature of the furan reactants on the reaction mechanisms and overall catalyst performance. 


\section{Experimental methods}

\subsection{Catalyst preparation}

HZSM-5 zeolite (Süd-Chemie, Si/Al = 13) was used as a starting material. Ga/HZSM-5 samples were prepared via incipient wetness impregnation of HZSM-5 zeolite with an aqueous solution of gallium nitrate $\left(\mathrm{Ga}\left(\mathrm{NO}_{3}\right)_{3}\right.$, Alfa Aesar, 99.9\%, metal based) followed by drying at $110{ }^{\circ} \mathrm{C}$ overnight and subsequent calcination at $550^{\circ} \mathrm{C}$ for $5 \mathrm{~h}$ under static air. The calcined catalysts were then treated in a $\mathrm{H}_{2} / \mathrm{Ar}(1 / 3)$ flow at $550{ }^{\circ} \mathrm{C}$ for $7 \mathrm{~h}$ to ensure a high dispersion of Ga inside the zeolite micropores. ${ }^{29}$ These catalysts samples are denoted further in the text as $\mathrm{Ga}(\mathrm{x}) / \mathrm{HZSM}-5$, where $\mathrm{x}$ stands for the weight percentage of Ga.

\subsection{Catalyst characterization}

The chemical composition ( $\mathrm{Si} / \mathrm{Al}$ ratio and Ga content) of the prepared materials was determined by elemental analysis using the ICP-OES technique. A Spectro CIROS CCD ICP optical emission spectrometer with axial plasma viewing was used for these measurements. Prior to analysis, the zeolite samples were dissolved in a 1:1:1 mixture by weight of $\mathrm{HF}(40 \%), \mathrm{HNO}_{3}(60 \%)$, and $\mathrm{H}_{2} \mathrm{O}$.

The acidic properties of the zeolites were determined by IR spectroscopy of adsorbed pyridine. Spectra were taken in the 4000-1000 $\mathrm{cm}^{-1}$ range using a Bruker Vertex 70v spectrometer. Samples were pressed into self-supporting wafers $(10-15 \mathrm{mg}$, diameter $1.3 \mathrm{~cm})$ and placed in an environmental cell. The samples were first pre-treated in $\mathrm{O}_{2}: \mathrm{N}_{2}\left(1: 4 \mathrm{vol}\right.$. ratio) flow at $550^{\circ} \mathrm{C}$ (heating rate $\left.5{ }^{\circ} \mathrm{C} / \mathrm{min}\right)$ to remove contaminants followed by cooling to $150{ }^{\circ} \mathrm{C}$ under dynamic vacuum $\left(\mathrm{p}<10^{-5} \mathrm{mbar}\right.$ ). Pre-treated samples were then exposed to excess pyridine vapour. After evacuation, IR spectra were recorded at different temperatures $\left(150-450{ }^{\circ} \mathrm{C}\right)$ under vacuum. For the quantification of Brønsted and Lewis acid sites, integral molar extinction coefficients (IMEC) of $0.73 \mathrm{~cm} / \mathrm{mol}$ and $1.11 \mathrm{~cm} / \mathrm{mol}$ respectively were used

30,31. Samples for CO adsorption measurements were prepared in the same manner. CO was adsorbed at $77 \mathrm{~K}$ in a concentration range from 0.1 to $2 \mathrm{CO} /[\mathrm{BAS}]$.

Powder X-ray diffraction patterns were obtained with a Bruker D2 PHASER system (Cu Ka radiation, scan speed $0.01^{\circ} \mathrm{s}, 2 \theta$ range $5-60^{\circ}$ ). The relative crystallinity of samples normalized to pristine HZSM-5 was evaluated by comparing the areas of the reflection peaks ( $h k l$ indices in parentheses) at $23.1^{\circ}(051)$,

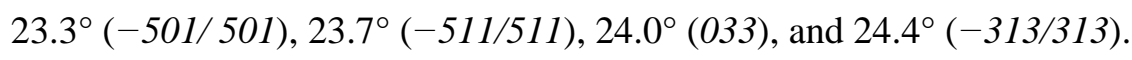

Textural properties were derived from Ar physisorption isotherms, which were recorded at $87.3 \mathrm{~K}$ using a Micromeritics ASAP-2020 apparatus. The samples were degassed at $450{ }^{\circ} \mathrm{C}$ prior to physisorption. The microporous volume was determined by the t-plot method using a thickness range from 3.5 to $4.5 \AA$. 
${ }^{27} \mathrm{Al}$ magic angle spinning nuclear magnetic resonance $\left({ }^{27} \mathrm{Al}\right.$ MAS NMR) were carried out with $11.7 \mathrm{~T}$ Bruker DMX500 NMR spectrometer with a Bruker 2.5-mm MAS probe head spinning at $25 \mathrm{kHz}$. The samples were hydrated prior to measurements.

\subsection{Catalytic aromatization of furanics}

Catalytic activity measurements were carried out in a quartz fixed-bed downstream reactor (i.d. $=4 \mathrm{~mm}, \mathrm{l}$ $=20 \mathrm{~cm}$ ). In a typical experiment, $0.5 \mathrm{~g}$ catalyst (sieve fraction $250-500 \mu \mathrm{m}$ ) was held in place by a quartz wool plug. Prior to the measurements, zeolites were pre-treated under He flow at $550{ }^{\circ} \mathrm{C}$ (heating rate $5{ }^{\circ} \mathrm{C} / \mathrm{min}$ ) to remove water and other possible contaminants and then cooled down to the reaction temperature. Calibrated thermal mass-flow controllers (Brooks) were used to feed gases to the reactor. Furanic compounds were introduced in the fed by leading a gas flow through a thermostated saturator. Furan (Sigma Aldrich, $\geq 99$ \%), 2-methylfuran (2-mF, Sigma Aldrich, 99\%) and 2.5-dimethylfuran (2.5dMF, Sigma Aldrich, $99 \%$ were used. Reaction products were analysed using online gas chromatography (Trace GC 1300, Thermo) and mass spectrometry (Pfeiffer Omnistar GSD 301 T3 MS) instruments, placed downstream the reactor. A TCD detector equipped with RT-Q-Bond column (length $20 \mathrm{~m}$; i.d. $0.32 \mathrm{~mm}$; d.f. $10 \mu \mathrm{m}$ ) was used to analyse the light fraction of the reaction products including water, $\mathrm{CO}_{\mathrm{x}}, \mathrm{C} 1-\mathrm{C} 4$ hydrocarbons. Aromatic products were analysed with a FID detector coupled with an Rxi-5Sil MS column (length $30 \mathrm{~m}$; i.d. $0.32 \mathrm{~mm}$; d.f. $0.25 \mu \mathrm{m}$. For qualitative analysis and identification of individual compounds the reaction products were collected in a cold trap (cooled with liquid nitrogen) and then analysed with a GC-MS instrument (Shimadzu MS GCMS-QP 5050a). A mixture of GC standards was use to confirm the assignment of the main components. The reaction selectivity, conversion and yield were calculated as described in Scheme 1.

$$
\begin{aligned}
& \text { (I) } x_{i}(t)=\frac{n_{i}^{\text {out }}}{n_{i}^{\text {in }}} \\
& \text { (II) } s_{k}(t)=\frac{n_{k}^{\text {out }}}{n_{i}^{\text {in }}-n_{i}^{\text {out }}} *\left|\frac{\mu_{i}}{\mu_{k}}\right| \\
& \text { (III) } X_{\Sigma}\left(C_{\text {based }}\right)=\sum_{i} \mu_{i} * \int_{0}^{t}\left(n_{i}^{\text {in }}-n_{i}^{\text {out }}\right) d t \\
& \text { (IV) } S_{k}=\frac{\mu_{k} * \int_{0}^{t} n_{k}^{\text {out }} d t}{X_{i}} \\
& \text { (V) } Y_{k}=\mu_{k} * \int_{0}^{t} n_{k}^{\text {out }} d t=S_{k} * X_{i}
\end{aligned}
$$

Scheme 1. (I) - conversion at t; (II) - carbon based selectivity to a product $k$ at $t$ where $n_{j}-$ concentration of compound and $\mu_{j}$ - number of carbon atoms in $k$; (III) - overall C based conversion at $\mathrm{t}$; 
(IV) - overall C based selectivity to a product $k$; (V) - overall C based yield of a product $k$. Cumulative (overall) parameters were calculated at $t$ such that $x(t)=75 \%$.

\subsection{TPR-IR experiments}

TPR-IR experiments were carried out in an environmental IR cell. Prior to furan or 2,5-dimethylfuran dosing, samples were pre-treated using the same procedure as for pyridine adsorption. The pre-treated sample were cooled to $50^{\circ} \mathrm{C}$ in a dynamic vacuum and then a background spectrum was recorded. Then, the zeolite was exposed to furan or 2,5-dimethylfuran vapour using a sample loop connected to the thermostated saturator. Adsorption was followed with IR spectroscopy and saturation was considered when the spectra did not change anymore. After saturation, the cell was evacuated and heated to $550{ }^{\circ} \mathrm{C}$ at a ramp rate of $5 \% \mathrm{~min}$. Spectra were recoded every $3 \mathrm{~min}$ in the spectral range of $4000-1000 \mathrm{~cm}^{-1}$. 


\section{Results and discussion}

We compared a set of Ga-modified ZSM-5 catalysts with HZSM-5 for the aromatization of furanic model compounds. The Ga-loading in the ion-exchanged Ga/ZSM-5 zeolites was varied between 1 - 4 wt. \%. After ion-exchange, the zeolites were calcined at $550{ }^{\circ} \mathrm{C}$ and then reduced in $\mathrm{H}_{2}$ at $550{ }^{\circ} \mathrm{C}$ in order to improve the Ga dispersion. ${ }^{32}$ The resulting zeolite samples were thoroughly characterized for their physical chemical properties and the main results are listed in the Table 1. According to XRD, all of the Ga/HZSM-5 samples retain the MFI topology of the parent zeolite with no indications of a decrease in crystallinity nor formation of amorphous silica or large Ga-oxide agglomerates. In line with this, $\mathrm{Ar}$ physisorption measurements show that the zeolites retain their microporous nature. The presence of intrazeolitic Ga species can be derived from a decrease of the micropore surface area for samples with a Ga loading higher than 1 wt. \%. ${ }^{27} \mathrm{Al}$ MAS NMR spectroscopy shows that the parent sample contains less than $10 \%$ extraframework $\mathrm{Al}$. The structure of framework $\mathrm{Al}$ sites is not significantly affected by the presence of Ga $\left({ }^{27} \mathrm{Al}\right.$ MAS NMR spectra and spectra of adsorbed pyridine are shown on Figure S1.a,b).

Table 1. Physical-chemical properties of the Ga/HZSM-5 catalysts.

\begin{tabular}{|l|c|c|c|c|c|c|c|c|}
\hline & $\begin{array}{c}\mathrm{Ga} / \mathrm{Al}, \\
\text { atomic }^{\mathrm{ratio}}\end{array}$ & $\begin{array}{c}\text { BAS/LAS } \\
(\mu \mathrm{mol} / \mathrm{g})^{\mathrm{b}}\end{array}$ & $\begin{array}{c}\text { Total } \\
\text { acidity } \\
(\mu \mathrm{mol} / \mathrm{g})^{\mathrm{b}}\end{array}$ & $\begin{array}{c}\text { Exchange } \\
\text { degree, } \%\end{array}$ & $\begin{array}{c}v(\mathrm{CO} \cdots \mathrm{HO})^{\mathrm{c}}, \\
\mathrm{cm}^{-1}\end{array}$ & $\begin{array}{c}\mathrm{S}_{\text {total, }} \\
\mathrm{m}^{2} / \mathrm{g}\end{array}$ & $\begin{array}{c}\mathrm{S}_{\text {micro, }} \\
\mathrm{m}^{2} / \mathrm{g}\end{array}$ & $\begin{array}{c}\mathrm{V}_{\text {micro, }} \\
\mathrm{m}^{2} / \mathrm{g}\end{array}$ \\
\hline $\begin{array}{l}\text { HZSM-5 } \\
\text { HZSM-5 }\end{array}$ & 0 & $950 / 107$ & 1057 & 0 & 2174 & 321.3 & 281.8 & 0.11 \\
\hline $\begin{array}{l}\text { Ga(2)/ } \\
\text { HZSM-5 }\end{array}$ & 0.23 & $556 / 526$ & 1082 & 41 & 2174 & 331.3 & 280.8 & 0.11 \\
\hline $\begin{array}{l}\text { Ga(4)/ } \\
\text { HZSM-5 }\end{array}$ & 0.43 & $487 / 599$ & 1086 & 48 & 2174 & 292.5 & 219 & 0.10 \\
\hline
\end{tabular}

a) Measured by ICP; b) IR of adsorbed pyridine; c) IR of adsorbed CO.

IR spectroscopy was used to investigate the strength and number of acid sites of the Ga/ZSM-5 zeolites. Spectra of adsorbed CO reveal that the strength of the BAS is not affected by the presence of Ga. Thus, adsorption of CO on re-oxidized catalysts leads to formation of two bands at 2174 and $2140 \mathrm{~cm}^{-1}$ corresponding to $\mathrm{CO}$ complexes with framework hydroxyls and physically adsorbed CO, respectively. ${ }^{33-}$

${ }^{35}$ Pyridine as a probe was used to quantitatively determine the amount of BAS and LAS (spectra in Figure S1a.). Table 1 shows that the amount of BAS decreases with the Ga content, implying that ion- 
exchange/calcination/reduction treatment leads to replacement of protons by cationic Ga species. This exchange also gives rise to LAS, whose concentration reaches a plateau after a certain degree of exchange (Figure 1a). The variation of the $\mathrm{Ga} / \mathrm{BAS}$ and $\mathrm{Ga} / \mathrm{LAS}$ ratio with $\mathrm{Ga}$ content can be attributed to the formation of cationic Ga-oxo clusters. ${ }^{3637}$ Taken together with earlier studies on the role of calcination/reduction on Ga speciation in ZSM-5 zeolites, these data evidence a uniform distribution of Ga cations in the activated Ga/ZSM-5 zeolite samples.
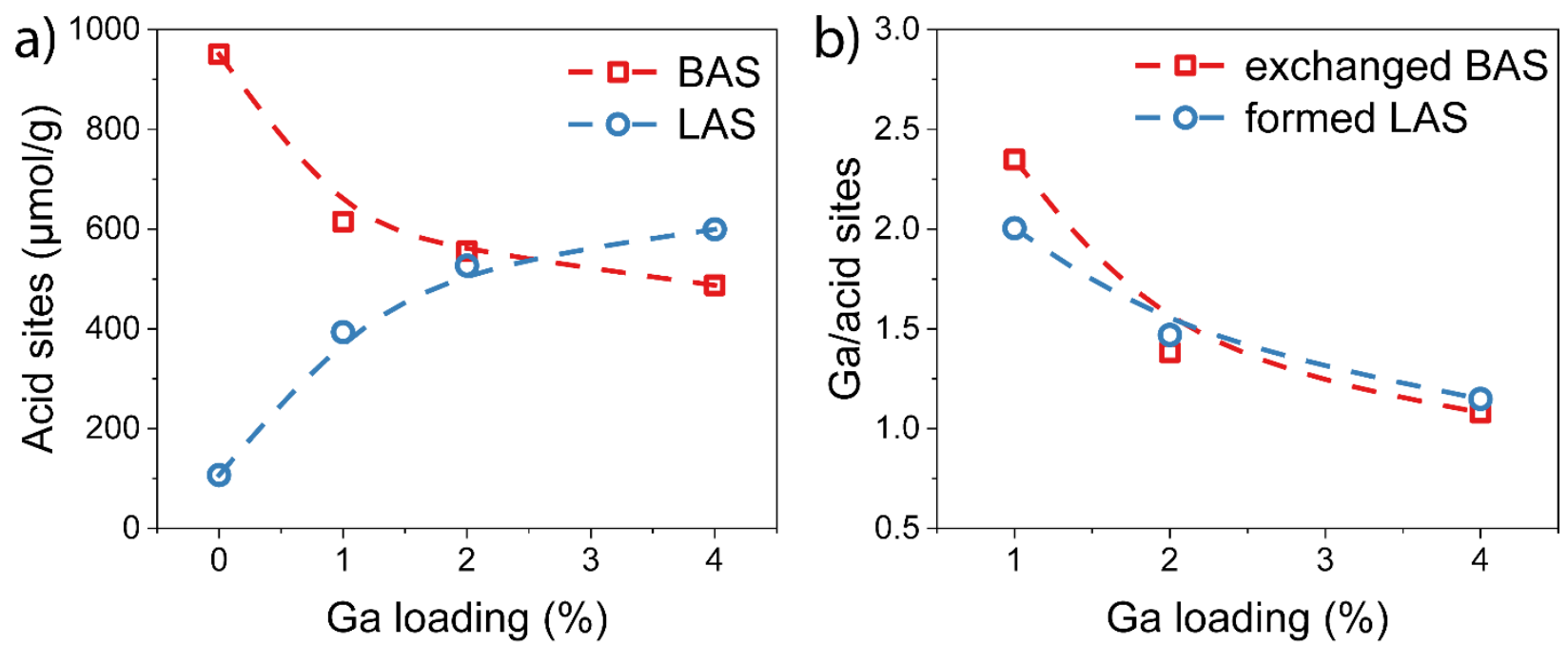

Figure 1. Acidic properties of the Ga/HZSM-5 catalysts as determined by IR spectroscopy of adsorbed pyridine and elemental analysis: a) Concentration of LAS and BAS as a function of Ga loading in ZSM-5 catalysts and b) fraction of exchanged BAS and formed LAS compared to the exchange degree.

We next investigated the impact of Ga promotion of HZSM-5 on the aromatization of 2,5-dMF at $450{ }^{\circ} \mathrm{C}$. A combination of a low WHSV $\left(0.05 \mathrm{~h}^{-1}\right)$ and fast GC analysis allowed following the reaction analytically, involving regimes of high conversion and deactivation, with a temporal resolution of 0.16 $\min ^{-1}$. The distribution of the main reaction products as function of time on stream are shown in Figure S4. These data provide information about the dependence of the reaction on contact time. Similarly to methanol conversion on zeolites, deactivation of the catalyst in a fixed bed is progressive along the reactor from the inlet to the outlet. Deactivation starts at the top of the bed (down-flow mode). Therefore, the amount of active catalyst decreases as function of time on stream. ${ }^{38,39}$

The reaction profiles shown in Figure S4 show that the concentration of olefins (ethylene and propylene) increased during deactivation (and therefore with contact time). This implies that olefinic compounds formed during earlier reaction stages are converted to aromatics in the presence of Ga species. Besides, the changes in aromatic product distribution indicate that alkylation, dealkylation, transalkylation and isomerization reactions play an important role in the overall process. 
Figure 2 compares the catalytic performance data of the Ga/ZSM-5 zeolite with HZSM-5. The corresponding cumulative carbon yields are collected in Table S1. After an initial regime of complete consumption of 2,5-dMF, the conversion rapidly drops to zero. The catalyst lifetime is highest for HZSM5 and becomes lower with increasing Ga content. Figure $2 b$ shows that the aromatics yield increases with the Ga content. The highest cumulative BTX yield of $\sim 40 \%$ is obtained for Ga(4)/ZSM- 5 . The positive effect of $\mathrm{Ga}$ on the aromatics yield in the conversion of furan has been associated before to the aromatization activity of cationic Ga species in zeolites ${ }^{3740}$. The present observations of higher aromatics and lower light olefins yield with increasing Ga content (Figure 2d) confirms that olefinic products are converted to aromatics by active Ga species. The correlation between BTX selectivity and Ga content as shown on Figure 2c suggests that influence of Ga species is more complex and both BAS and LAS play role in the reaction. The faster deactivation with increasing Ga content can be correlated to a higher yield of aromatics, which are the likely precursors to carbonaceous deposits that cannot leave the micropores and therefore deactivate the catalyst.
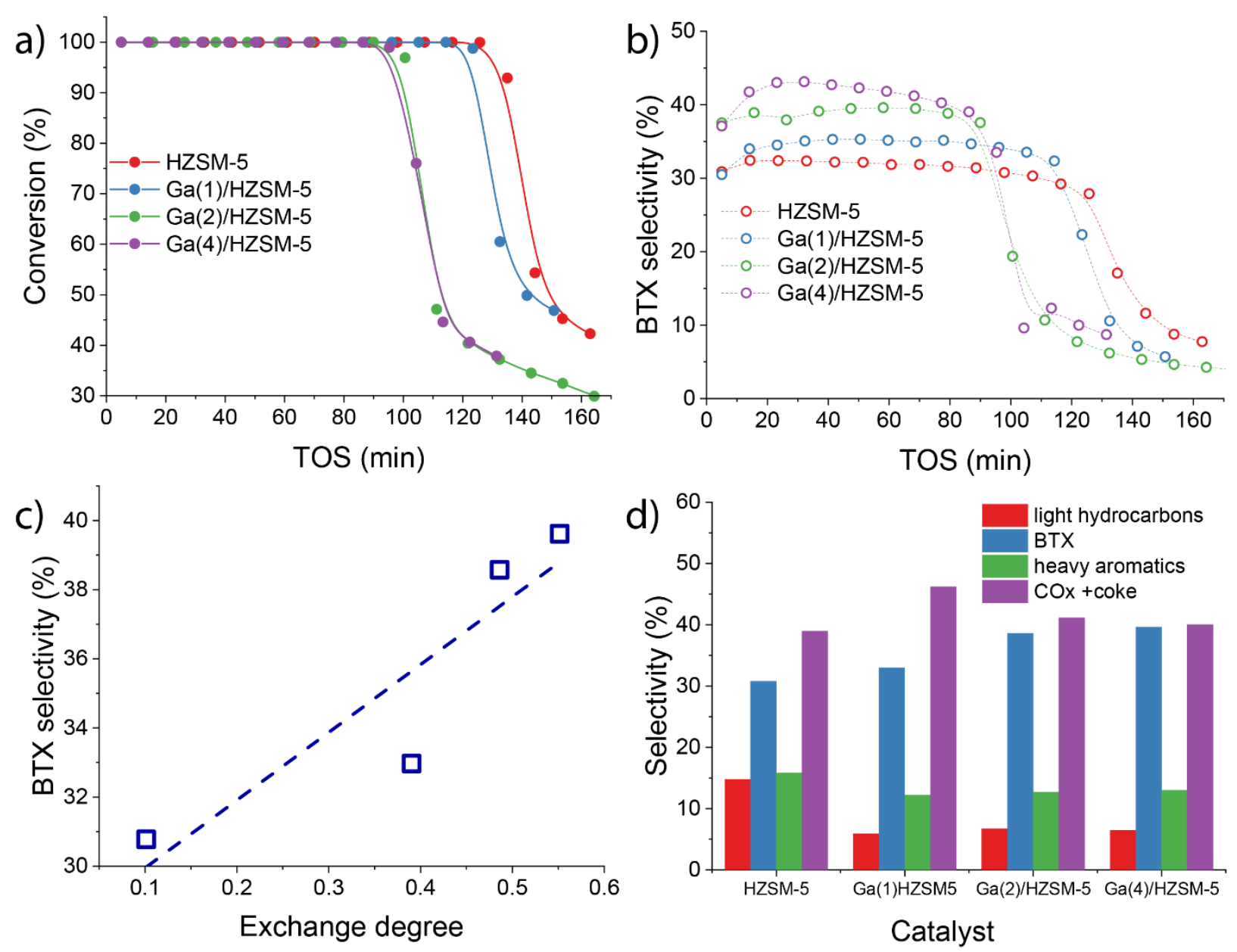
Figure 2. Evolution of 2,5-dMF conversion (a) and BTX yield (b) during conversion of 2,5-dMF over ZSM-5 catalysts with different Ga loading; (c) total yield of BTX aromatics as a function of the exchange degree $\left(\mathrm{C}_{\mathrm{LAS}} /\left(\mathrm{C}_{\mathrm{LAS}}+\mathrm{C}_{\mathrm{BAS}}\right)\right.$ and (d) total selectivity to the principal groups of products. Conditions: reaction temperature $450{ }^{\circ} \mathrm{C}$; $\mathrm{p}(2,5-\mathrm{dMF}) 0.2 \mathrm{kPa}$; atmospheric pressure; carrier - $100 \mathrm{~mL} / \mathrm{min}$ Ar.

To investigate the influence of the contact time on the product distribution we performed catalytic experiments with higher (WHSV $=0.15 \mathrm{~h}^{-1}$ ) and lower (WHSV $=0.025 \mathrm{~h}^{-1}$ ) space velocity. The results (Figure S5) show that both product distribution and the cumulative amount of converted furan are not significantly affected by the space velocity. The deactivation rate, on the other hand, increases proportionally with the space velocity.

To get a better insight into the mechanism of 2,5-dMF aromatization, the catalytic process was investigated by temperature-programmed reaction of 2,5-dMF monitored by online mass spectrometry (TPR-MS) and with IR spectroscopy (TPR-IR). The mass spectra of the reaction effluent identifying the main reaction products during the TPR-MS of 2,5-dMF are shown in Figure $3 a$ and $3 b$ for HZSM-5 and Ga(4)/HZSM-5, respectively. Figure 4 shows the corresponding IR spectra. The TPR-MS results show that no gaseous reaction products are observed below $300^{\circ} \mathrm{C}$, although 2,5-dMF is completely converted. This suggests that 2,5-dMF is converted to oligomeric species in the zeolite micropores. Formation of such oligomeric species has been observed before for furan and thiophene, the sulphur analogue of furan. ${ }^{4142}$ Above $300{ }^{\circ} \mathrm{C}$, the mass spectra evidence the formation of a range of products in the gas phase. Two main groups of products were identified, that is (i) light hydrocarbons including ethylene and propylene ( $\mathrm{m} / \mathrm{z}$ 28, 27, 26 and 41, 39, 42 respectively) and (ii) BTX (major m/z B: 78, 77; T: 91, 92; X: $91,106,105)$. The qualitative concentration profiles of the main products are shown in Figure S6. The formation of BTX started at $300{ }^{\circ} \mathrm{C}$ and reached a maximum between $375{ }^{\circ} \mathrm{C}$ and $525{ }^{\circ} \mathrm{C}$. At higher temperature, the benzene selectivity increased markedly, which can be explained by the higher thermodynamic stability of benzene compared to toluene and xylenes. ${ }^{43}$ The overall selectivity to aromatics drops at temperatures above $525{ }^{\circ} \mathrm{C}$ (Figure 3) due to the enhanced coke formation. At the same time the conversion of ethylene and propylene increases for Ga(4)/ZSM-5, implying that Ga species promote activation of light hydrocarbons formed during earlier reaction stages (Figure S6). 


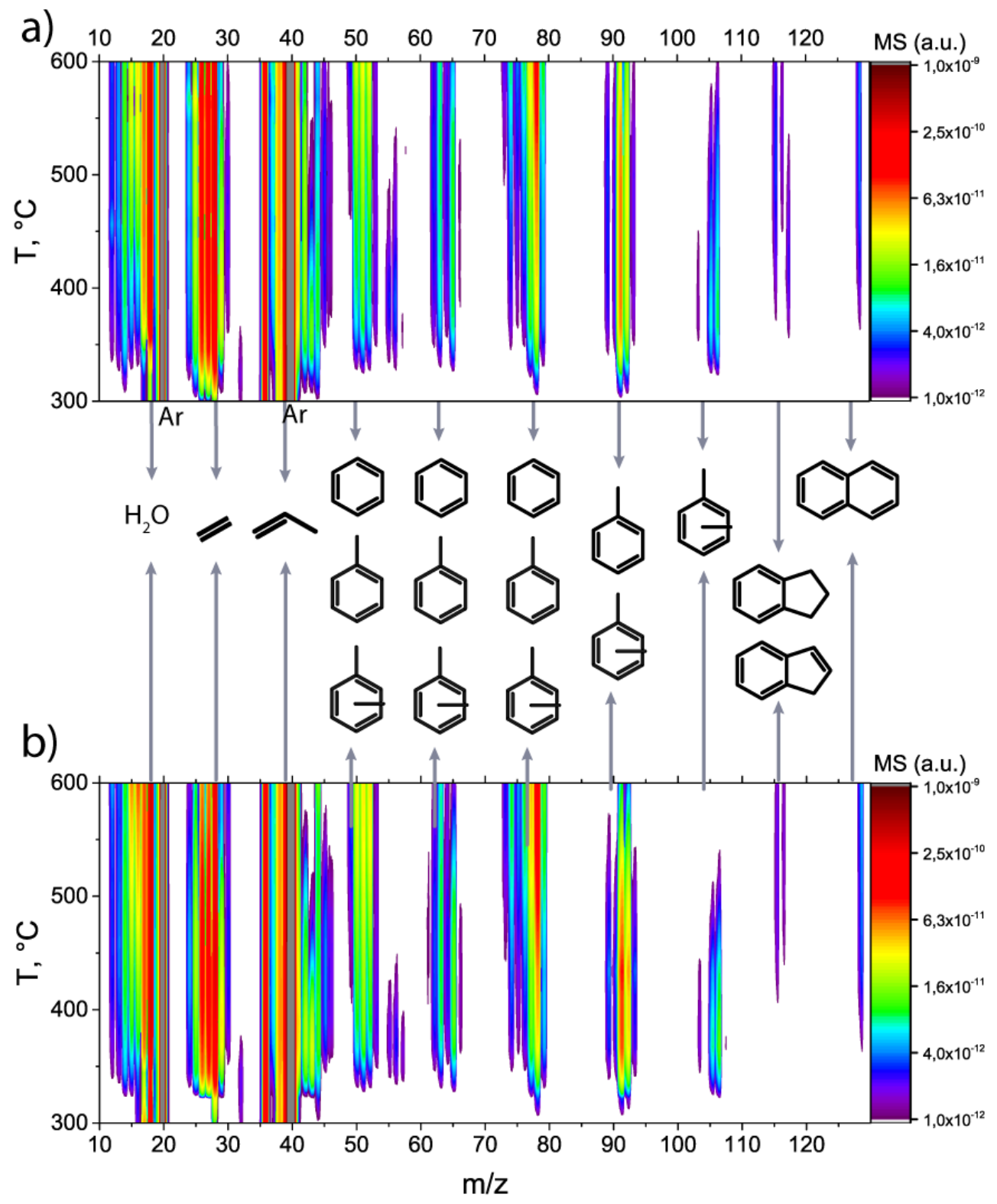

Figure 3. Contour plot constructed of mass spectra recorded during TPR of 2,5-dMF over the parent ZSM-5 (a) and $4 \% \mathrm{Ga}$ samples (b). Conditions: ramp rate $5{ }^{\circ} \mathrm{C} / \mathrm{min}$; $\mathrm{p}(2,5-\mathrm{dMF})=0.2 \mathrm{kPa}$; atmospheric pressure; carrier -100 $\mathrm{mL} / \mathrm{min} \mathrm{Ar}$.

The $T P R-I R$ results provide additional insight into the dependence of the reaction on temperature. The assignment of the IR bands discussed below is given in Table 2. Adsorption of 2,5-dMF on HZSM-5 at $50{ }^{\circ} \mathrm{C}$ leads to the disappearance of the $v(\mathrm{OH})$ IR band at $3610 \mathrm{~cm}^{-1}$ assigned to BAS and formation of broad bands in a range $3000-3500 \mathrm{~cm}^{-1}$ corresponding to perturbed hydroxyls. ${ }^{35}$ This indicates that adsorbed species interact with Brønsted acid sites. The new bands at $1750-1300 \mathrm{~cm}^{-1}$ and at $2650-3200$ $\mathrm{cm}^{-1}$ are significantly different from the ones observed for 2,5-dMF adsorbed on NaZSM-5 and on pure 
2,5-dMF. Some of the bands (2924, 1574, 1525, 1385, $1346 \mathrm{~cm}^{-1}$ ) are similar and correspond to weakly adsorbed 2,5-dMF. The spectra of 2,5-dMF adsorbed on HZSM-5 and NaZSM-5 are shown on Figure S7. IR spectra of pure 2,5-dMF in the liquid phase are shown on Figure S8. The oligomerization of furanics is evidenced by the appearance of a broad band in the $1350-1450 \mathrm{~cm}^{-1}$ region, which can be attributed to C$\mathrm{H}$ deformation vibrations and a broad band in the $1600-1700 \mathrm{~cm}^{-1}$ assigned to $\mathrm{C}=\mathrm{C}$ stretching vibrations. The bands in the C-H stretching spectral region around $2910 \mathrm{~cm}^{-1}$ are also affected. ${ }^{44}$ The dominance of protonation and oligomerization pathways leading to the formation of confined intra-zeolite oligomeric species below $300{ }^{\circ} \mathrm{C}$ is additionally supported by UV-Vis and TGA measurements summarized in Figure S9.

Table 2. Assignment of the observed IR bands.

\begin{tabular}{|c|c|}
\hline Wavenumber $\left(\mathrm{cm}^{-1}\right)$ & Assignment \\
\hline 3610 & $\begin{array}{l}v(\mathrm{O}-\mathrm{H}) \text { vibration of Brønsted acid } \\
\text { sites }\end{array}$ \\
\hline $3000-3500$ & $\begin{array}{l}v(\mathrm{O}-\mathrm{H}){ }^{35} \text { of perturbed Brønsted acid } \\
\text { sites }\end{array}$ \\
\hline $\begin{array}{l}\text { 2924, 1574, } 1525, \\
1385,1346\end{array}$ & $\begin{array}{l}v(\mathrm{C}-\mathrm{H}), \quad v(\mathrm{C}=\mathrm{C}) \quad \text { and } \quad \delta(\mathrm{C}-\mathrm{H}) \quad \text { of } \\
\text { physisorbed } 2,5-\mathrm{dMF}\end{array}$ \\
\hline $1350-1450$ & $\delta(\mathrm{C}-\mathrm{H})$ of oligomeric species \\
\hline $1600-1700$ & $v(\mathrm{C}=\mathrm{C})$ of oligomeric species \\
\hline 2910 & $v(\mathrm{C}-\mathrm{H})$ of oligomeric species ${ }^{44}$ \\
\hline $\begin{array}{l}1600, \quad 1590, \quad 1482, \\
1460,1420,1466,1385\end{array}$ & $\begin{array}{l}\text { Substituted aromatics: toluene and } \\
\text { xylenes }{ }^{45,46}\end{array}$ \\
\hline 1610 & $\begin{array}{l}\delta(\mathrm{C}-\mathrm{H}) \quad \text { of } \text { hydrogen-deficient } \\
\text { polyaromatic species }{ }^{47,48}\end{array}$ \\
\hline 1540,1524 & Substituted naphthalenes ${ }^{47,48}$ \\
\hline 1494 & $\begin{array}{l}\text { Highly unsaturated } \quad(\mathrm{C}=\mathrm{C}=\mathrm{C}) \\
\text { species }^{47,48}\end{array}$ \\
\hline
\end{tabular}

Above $300{ }^{\circ} \mathrm{C}$, these confined oligomeric species start decomposing to produce aromatic products observed by MS. The decomposition of 2,5-dMF oligomers manifests itself in the IR spectra via the regeneration of the $\mathrm{OH}$ stretching band at $3610 \mathrm{~cm}^{-1}$ and the decreasing intensity of the bands in the 1600$1700 \mathrm{~cm}^{-1}$ and $1350-1450 \mathrm{~cm}^{-1}$ regions. At elevated temperature several new bonds are formed in the $1300-1800 \mathrm{~cm}^{-1}$ region. Some bonds can be attributed to light aromatic species formed in zeolite such as xylene and toluene $\left(1600,1590,1482,1460,1420,1466,1385 \mathrm{~cm}^{-1}\right) .{ }^{45,46}$ These bands are relatively 
weak, which precludes a meaningful deconvolution and identification of individual species. Most of these species are removed through desorption from the zeolite at temperature above $500{ }^{\circ} \mathrm{C}$. For both HZSM-5 and $\mathrm{Ga}(4) / \mathrm{HZSM}-5$, a band at $1610 \mathrm{~cm}^{-1}$ is observed which can be assigned to bending $\mathrm{C}-\mathrm{H}$ vibrations of hydrogen-deficient polyaromatic species. The intensity of this band is significantly higher for HZSM-5 as compared to $\mathrm{Ga}(4) / \mathrm{HZSM}-5$. Another common feature appears at around $1540 \mathrm{~cm}^{-1}$ can be related to substituted naphthalenes. ${ }^{47,48}$ Interestingly, the structure of the spectra in this region for HZSM-5 is more complex and includes two more bands at $1524 \mathrm{~cm}^{-1}$ and $1494 \mathrm{~cm}^{-1}$, which can be attributed respectively to different alkylated naphthalenes and to unsaturated $\mathrm{C}=\mathrm{C}=\mathrm{C}$ moieties. These observations evidence an important role of highly unsaturated aromatic and aliphatic species in the overall reaction mechanism.
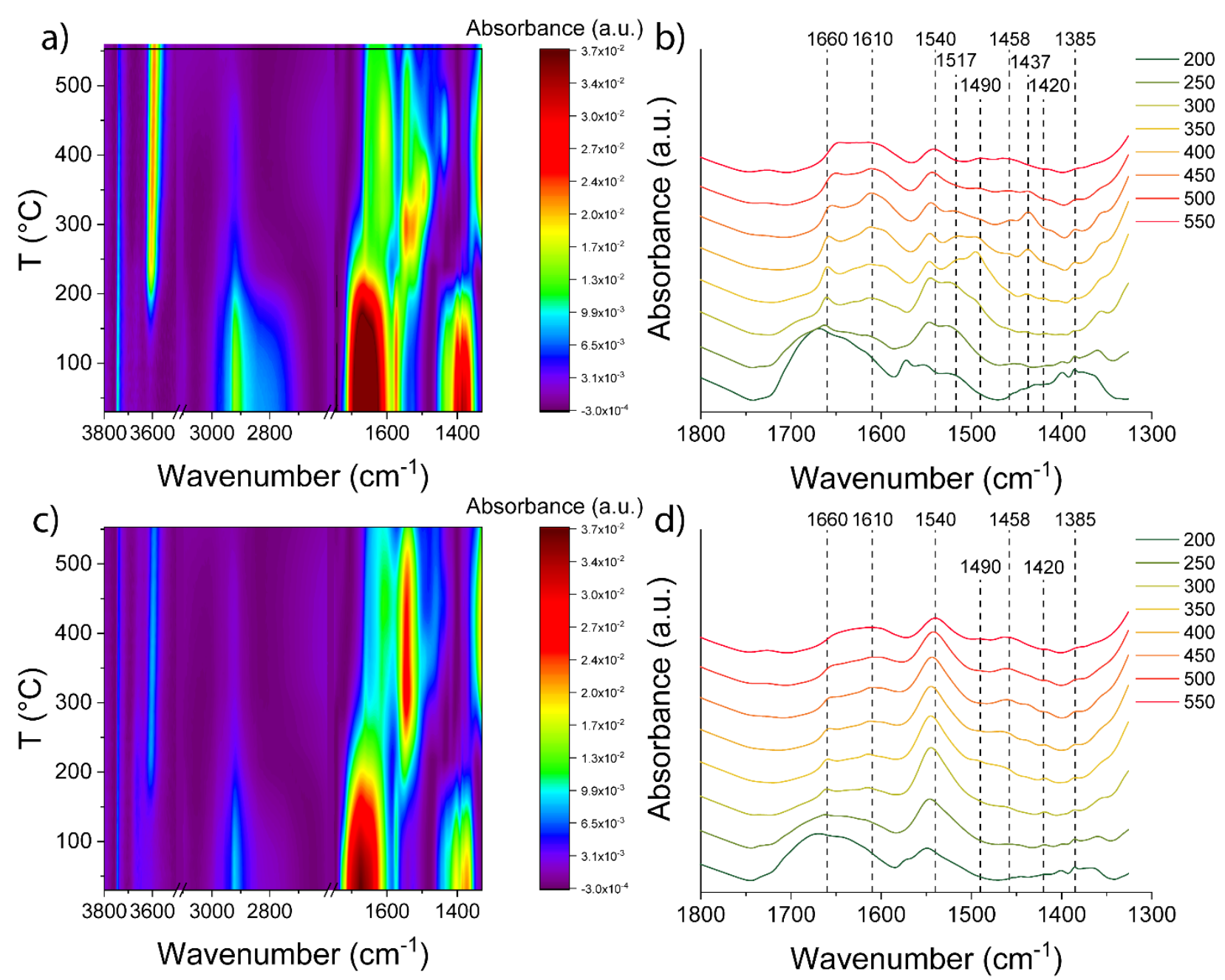

Figure 4. Contour maps constructed of IR spectra recorded during TPR of 2,5-dMF over the parent ZSM-5 (a,b) and $\mathrm{Ga}(4) / \mathrm{HZSM}-5$ samples (c,d). Conditions: ramp rate $5{ }^{\circ} \mathrm{C} / \mathrm{min}$; $\mathrm{p}(2,5-\mathrm{dMF})=0.2 \mathrm{kPa}$; atmospheric pressure; carrier - $100 \mathrm{~mL} / \mathrm{min} \mathrm{Ar}$; spectra are normalized by weight of the pellet. 
Another important difference between the Ga(4)/HZSM-5 and HZSM-5 catalysts identified by the IR spectroscopy is in the amount of oligomerized 2,5-dMF inside the pores at low temperature. Associated with oligomerization, the chemisorption of 2,5-dMF is much more pronounced on HZSM-5 as is seen from the higher intensity of bands in the $1600-1700 \mathrm{~cm}^{-1}$ and $1350-1450 \mathrm{~cm}^{-1}$ regions. Accordingly, for HZSM-5 the desorption of 2,5-dMF takes place at a significantly higher temperature. On the other hand, the spectra of the Ga(4)/HZSM-5 catalyst feature a much narrower and better-defined band at $1550 \mathrm{~cm}^{-1}$ due to confined aromatics, which is in line with the promoting effect of Ga on the BTX selectivity. In other words, Ga species suppress formation of highly unsaturated polyaromatic species and promote the formation of products that can be desorbed from the zeolite. This is in line with the catalytic data showing that the selectivity towards heavier aromatics including naphthalene and methylated naphthalenes is higher for HZSM-5 than for Ga(4)/HZSM-5. Moreover, the TGA data reveal a difference in coke properties between HZSM-5 and Ga(4)HZSM-5. Coke formed on HZSM-5 has a clear "soft" component, which can be related to lighter polyaromatic intrazeolite species. (Figure S10)

We further investigated the effect of substituents on the furan ring by evaluating the aromatization of furan and 2-methylfuran (2-MF). These furanic compounds as well as 2,5-dMF can be directly obtained from biomass. ${ }^{4916}$ Figure 5 summarizes results for HZSM-5 and Ga(4)/HZSM- 5 catalysts at $450^{\circ} \mathrm{C}$. The detailed quantification of all reaction products is provided in Table S1. In line with the above discussion on the competition between aromatization and cracking reaction pathways, the Ga-containing catalyst provides an increased selectivity to BTX with a concomitant decrease in undesirable light hydrocarbons from all three substrates (Figure $4 \mathrm{~b}$ and c, respectively). The catalytic tests reveal that the nature of the furanic substrate strongly influences the mechanism of the deoxygenation accompanying the aromatization reaction. Note that from the carbon-efficiency perspective oxygen removal via dehydration is preferred over decarbonylation or decarboxylation. Whereas deoxygenation via $\mathrm{CO}_{\mathrm{x}}$ removal dominates the conversion of furan, the presence of the methyl substituents for 2-MF and 2,5-dMF effectively promotes the dehydration reaction path. (Figure 5a). We infer that these differences are related to a more facile decarbonylation of a primary alcohol intermediate generated upon the ring-opening of furan as compared to the secondary alcohols generated from 2,5-dMF, for which the dehydration reaction is much more favourable.

An important finding of our studies contrasting an earlier report ${ }^{23}$ is that the presence of Ga in the catalyst has only a minor influence on the preferred deoxygenation path. The distribution of oxygencontaining products obtained with HZSM-5 and Ga(4)/HZSM-5 catalysts is very similar for all studied substrates. This implies that the initial ring-opening and the deoxygenation processes are catalysed solely by the Brønsted acid sites. 


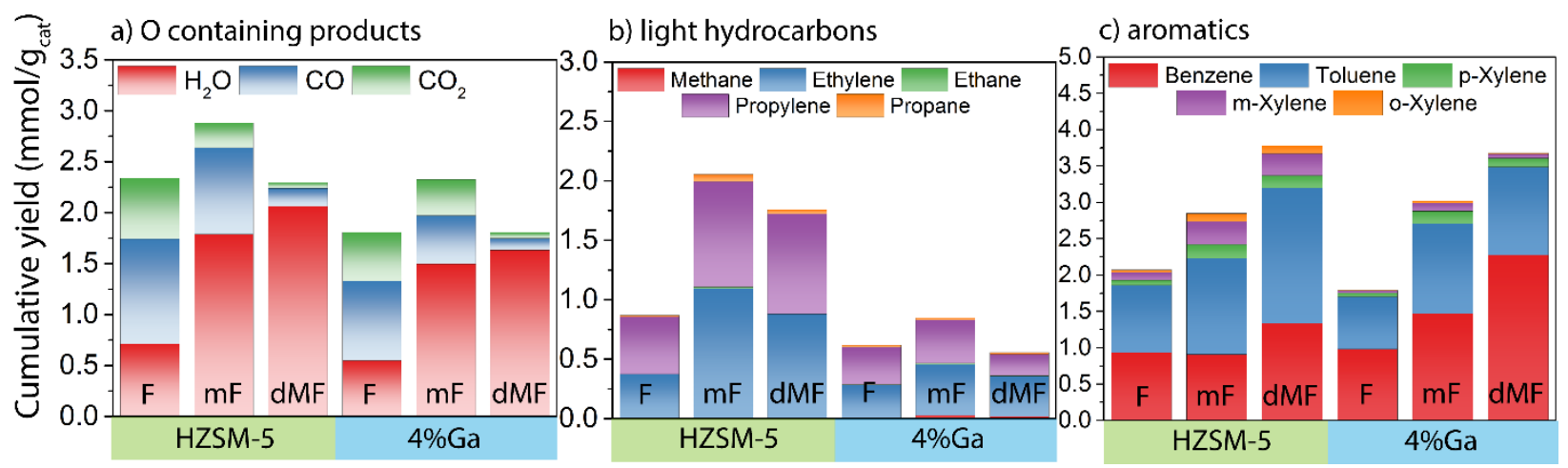

Figure 5. Total distribution of obtained products yields during conversion of Furan, 2-MF, 2,5-dMF over parent ZSM-5 and 4\%Ga catalysts: (a) oxygen-containing products; (b) light hydrocarbons; (c) BTX. Conditions: reactor temperature $450^{\circ} \mathrm{C}$; $\mathrm{p}$ (Furans) $0.2 \mathrm{kPa}$; atmospheric pressure; carrier $-100 \mathrm{~mL} / \mathrm{min}$ Ar.

Independent of the catalyst, the aromatization efficiency decreases for less substituted substrates. To understand how the reactivity and catalytic mechanism are affected by the nature of the substrate, we turned again to operando TPR-IR spectroscopy. Comparison of the results obtained with furan (Figure 6) and 2,5-dMF (Figure 4) readily shows that furan adsorbs much more efficiently on the zeolites than its methylated counterpart. Extensive furan oligomerization upon contact with the zeolite is manifested by the observation that the respective IR spectra for both HZSM-5 and Ga(4)/HZSM-5 are dominated by the bands in the $1500-1600 \mathrm{~cm}^{-1}$ region, which are due to $\mathrm{C}=\mathrm{C}$ vibrations of confined oligomers. In contrast to 2,5-dMF, an increase of the temperature does not result in the regeneration of the band at $3610 \mathrm{~cm}^{-1}$ associated with BAS. This implies that the reaction of furan with BAS produces stable oligomers inside the zeolite pores that can only be decompose above $400{ }^{\circ} \mathrm{C}$ via a pyrolysis-type process, leading to the formation of broad bands at $1490 \mathrm{~cm}^{-1}, 1520 \mathrm{~cm}^{-1}$ and $1560 \mathrm{~cm}^{-1}$ corresponding to the substituted polyaromatic species as discussed above. Interestingly, no band at $1610 \mathrm{~cm}^{-1}$ was detected which suggests that the structure of coke species is different from coke species derived from furan and dimethylfuran. Similarly, no BAS regeneration was observed under the TPR conditions for the Ga(4)/HZSM-5 catalyst. For both HZSM-5 and Ga(4)/HZSM-5 appearance of bands 1140, 1400 and $1375 \mathrm{~cm}^{-1}$ is observed indicating formation of some light aromatic products at temperatures above $300{ }^{\circ} \mathrm{C}$. Most likely, formation of aromatics takes place via the aromatization of the decomposition products over the Gacontaining sites and BAS. This is very similar to the observations made for 2,5-dMF, where the decomposition of the oligomeric intermediates produced intra-zeolite species, which could then undergo further transformations involving BAS or extra-framework Ga species inside the zeolite pores. 

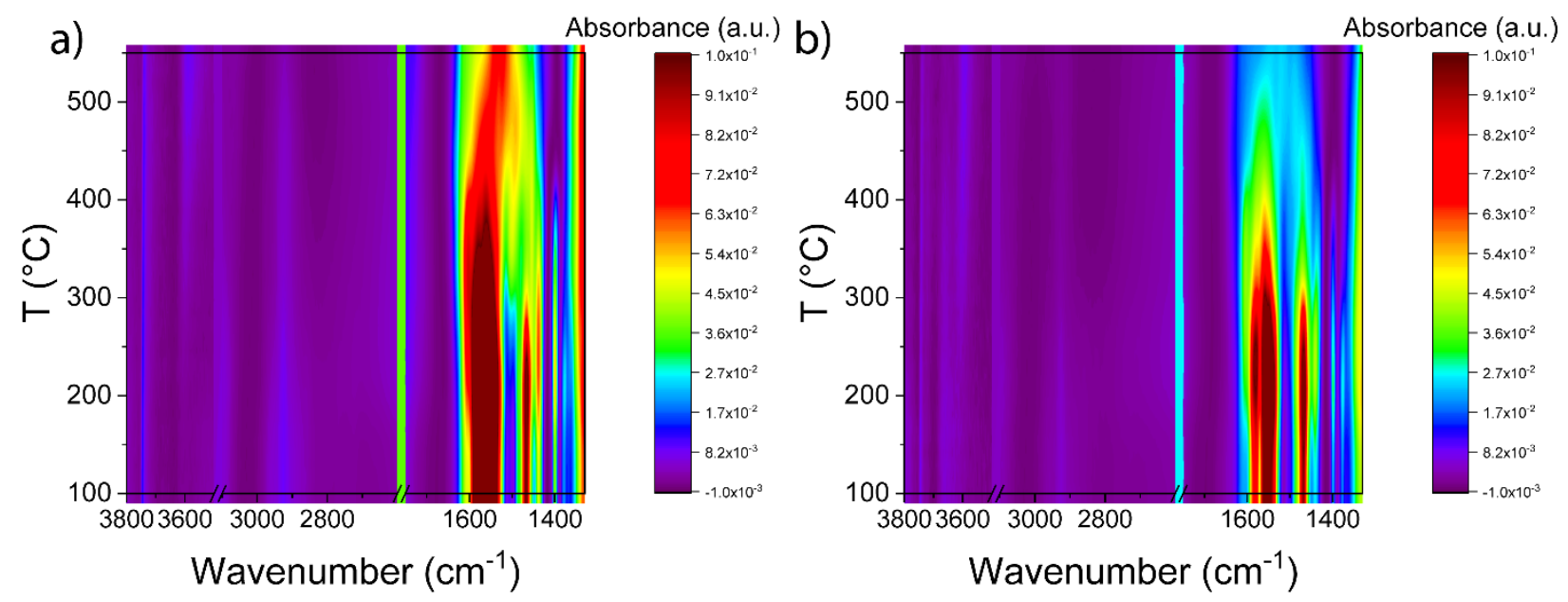

Figure 6. Heat maps constructed of IR spectra recorded during TPR of furan over the parent HZSM-5 (a) and $4 \%$ Ga samples (b). Conditions: ramp rate $5{ }^{\circ} \mathrm{C} / \mathrm{min}$; $\mathrm{p}(2,5-\mathrm{dMF})=0.2 \mathrm{kPa}$; atmospheric pressure; carrier -100 $\mathrm{mL} / \mathrm{min}$ Ar.

The results presented thus far allow us to substantially update the mechanistic proposal for the aromatization of furanics over the zeolite-based catalysts (Scheme 2). The activation of furanes and their initial transformation and deoxygenation takes place over zeolitic BAS, whereas the catalytic role of Ga is related to later aromatization stages of the process. The activation of furanes starts with furan protonation. At low temperature, this step initiates a rapid cationic polymerization reaction which is most pronounced for the less substituted furanes. Similar processes have been used for selective staining in microspectroscopy studies of zeolite acidity ${ }^{50,51}$. The catalytic conversions involve protonated furan molecules, which are isomerized via a carbocation mechanism to reactive intermediates with terminal oxygencontaining moieties capable of subsequent deoxygenation via decarbonylation or dehydration reactions (Scheme 2). These steps yield linear unsaturated intermediates, which disproportionate over BAS and/or extraframework Ga sites to yield cracking and aromatization products. These desired reactions are accompanied by coking over zeolite BAS, resulting in a rapid catalyst deactivation. 


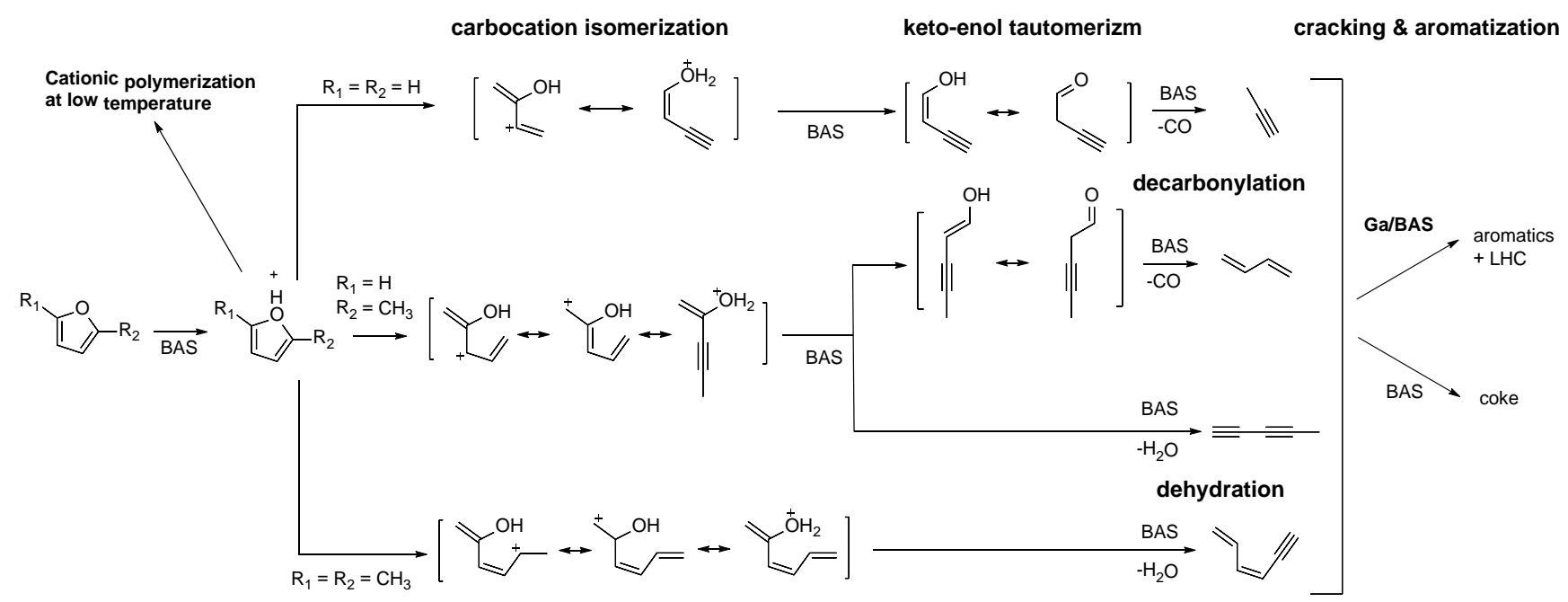

Scheme 2. Proposed reaction paths for the activation and the aromatization of furanes over acidic zeolites.

\section{Conclusions}

In this work we studied several aspects of the furanic compounds aromatization reaction on zeolite. First, we synthesised and characterized in detail Ga containing zeolites. By introducing Ga in zeolite it is possible to tune its acidic properties by substituting Brønsted acid sites and creating Lewis acid sites. We used those well define materials in the aromatization reaction of 2,5-dimethylfuran. To evaluate those catalysts we applied a sophisticated GC and MS technique with high temporal resolution which allowed us to analyse product composition on-line.

Conversion of furans over zeolite catalysts is a complicated process, involving (i) oligomerization in a temperature range from $<300^{\circ} \mathrm{C}$; (ii) dehydration, decarbonylation, cracking and aromatization in a range from $300{ }^{\circ} \mathrm{C}$ to $500{ }^{\circ} \mathrm{C}$ and (iii) extensive formation of coke above $500{ }^{\circ} \mathrm{C}$. By tuning the acidic properties of ZSM-5 catalyst it is possible to enhance the aromatic selectivity. Clearly, replacement of strong Brønsted acidity with Lewis acid sites upon exchanging Ga-species inside the pores, diminishes the cracking, while intrinsic aromatization selectivity of Ga/ZSM-5 is advantageous for the formation of BTX aromatics. The way that Ga is introduced, however, is critical for obtaining a BTX-selective catalyst, the reductive treatment is necessary to drive the Ga-species inside the pores onto the exchange sites and obtain a selective catalyst. Aromatization of methyl-substituted furans (2,5-dMF and 2-MF) is intrinsically more selective than that of furan, which is related to the different strength of their interactions with Brønsted acid sites and the very deoxygenation pathway. While furan mainly undergoes decarbonylation with an irreversible loss of about $20 \%$ of carbon, substituted furans are deoxygenated by dehydration, leading to a much higher carbon-efficiency.

\section{Acknowledgements}


This work was supported by the Netherlands Center for Multiscale Catalytic Energy Conversion (MCEC), an NWO Gravitation programme funded by the Ministry of Education, Culture and Science of the government of the Netherlands.

\section{References}

R. A. Sheldon, Green Chem., 2014, 16, 950-963.

Z. Sun, Nat. Catal., , DOI:10.1038/s41929-017-0007-z.

F.-X. Collard and J. Blin, Renew. Sustain. Energy Rev., 2014, 38, 594-608.

R. Rinaldi, R. Jastrzebski, M. T. Clough, J. Ralph, M. Kennema, P. C. A. Bruijnincx and B. M. Weckhuysen, Angew. Chemie - Int. Ed., 2016, 55, 8164-8215.

5 J. Zakzeski, P. C. A. Bruijnincx, A. L. Jongerius and B. M. Weckhuysen, Chem. Rev., 2010, 110, 3552-3599.

6 T. R. Carlson, T. P. Vispute and G. W. Huber, ChemSusChem, 2008, 1, 397-400.

7 M. M. Yung, W. S. Jablonski and K. A. Magrini-Bair, Energy \& Fuels, 2009, 23, 1874-1887.

8 J. J. Bozell and G. R. Petersen, Green Chem., 2010, 12, 539.

9 C. Angelici, B. M. Weckhuysen and P. C. A. Bruijnincx, ChemSusChem, 2013, 6, 1595-1614.

10 T. Ennaert, J. Van Aelst, J. Dijkmans, R. De Clercq, W. Schutyser, M. Dusselier, D. Verboekend and B. F. Sels, Chem. Soc. Rev., 2016, 45, 584-611.

11 P. C. A. Bruijnincx and B. M. Weckhuysen, Angew. Chemie - Int. Ed., 2013, 52, 11980-11987.

12 T. R. Carlson, G. A. Tompsett, W. C. Conner and G. W. Huber, Top. Catal., 2009, 52, 241-252.

13 R. H. Venderbosch, ChemSusChem, 2015, 8, 1306-1316.

14 Y. T. Cheng and G. W. Huber, ACS Catal., 2011, 1, 611-628.

15 D. A. Ruddy, J. A. Schaidle, J. R. Ferrell III, J. Wang, L. Moens and J. E. Hensley, Green Chem., 2014, 16, 454-490.

M. J. Climent, A. Corma and S. Iborra, Green Chem., 2014, 16, 516.

Y. Román-Leshkov, C. J. Barrett, Z. Y. Liu and J. a Dumesic, Nature, 2007, 447, 982-985.

J. Jae, G. A. Tompsett, A. J. Foster, K. D. Hammond, S. M. Auerbach, R. F. Lobo and G. W. Huber, J. Catal., 2011, 279, 257-268.

N. Kosinov, F. J. A. G. Coumans, E. A. Uslamin, A. S. G. Wijpkema, B. Mezari and E. J. M. Hensen, ACS Catal., 2017, 7, 520-529.

A. Corma, G. Huber, L. Sauvanaud and P. Oconnor, J. Catal., 2007, 247, 307-327.

N. Kosinov, A. Wijpkema, E. Uslamin, R. Rohling, F. Coumans, B. Mezari, A. Parastaev, A. Poryvaev, M. Fedin, E. Pidko and E. Hensen, Angew. Chemie Int. Ed., 2017, 630090, 1016-1020. 
Y.-T. Cheng, J. Jae, J. Shi, W. Fan and G. W. Huber, Angew. Chem. Int. Ed. Engl., 2012, 51, 1387-90.

24 J. L. Grandmaison, P. D. Chantal and S. C. Kaliaguine, Fuel, 1990, 69, 1058-1061.

25 S. Shao, H. Zhang, R. Xiao and D. Shen, Energy Technol., 2017, 5, 111-118.

R. Walsh, J. Chem. Soc. Faraday Trans. 1 Phys. Chem. Condens. Phases, 1976, 72, 2137.

J. Li, Y. Yu, X. Li, W. Wang, G. Yu, S. Deng, J. Huang, B. Wang and Y. Wang, Appl. Catal. B Environ., 2015, 172-173, 154-164.

28 S. Wang, Q. Cai, J. Chen, L. Zhang, X. Wang and C. Yu, Ind. Eng. Chem. Res., 2014, 53, 1393513944.

29 V. B. Kazansky, I. R. Subbotina, R. A. van Santen and E. J. M. Hensen, J. Catal., 2004, 227, 263269.

30 J. Datka, J. Catal., 1992, 135, 186-199.

31 C. A. Emeis, J. Catal., 1993, 141, 347-354.

32 V. Kanazirev, R. Dimitrova, G. L. Price, A. Y. Khodakov, L. M. Kustov and V. B. Kazansky, J. Mol. Catal., 1991, 70, 111-117.

33 L. M. Kustov, V. B. Kazanskii, S. Beran, L. Kubelkova and P. Jiru, J. Phys. Chem., 1987, 91, 5247-5251.

34 C. Otero Areán, G. Turnes Palomino, F. Geobaldo and A. Zecchina, J. Phys. Chem., 1996, 100, 6678-6690.

35 S. Bordiga, C. Lamberti, F. Bonino, A. Travert and F. Thibault-Starzyk, Chem. Soc. Rev., 2015, 44, 7262-7341.

A. Bhan and W. N. Delgass, Catal. Rev. - Sci. Eng., 2008, 50, 19-151.

E. J. M. Hensen, E. A. Pidko, N. Rane and R. A. Van Santen, Angew. Chemie - Int. Ed., 2007, 46, 7273-7276.

D. Mores, J. Kornatowski, U. Olsbye and B. M. Weckhuysen, Chem. - A Eur. J., 2011, 17, 28742884.

D. Rojo-Gama, L. Mentel, G. N. Kalantzopoulos, D. K. Pappas, I. Dovgaliuk, U. Olsbye, K. P. Lillerud, P. Beato, L. F. Lundegaard, D. S. Wragg and S. Svelle, J. Phys. Chem. Lett., 2018, 9, 1324-1328.

E. A. Pidko, E. J. M. Hensen and R. A. Van Santen, J. Phys. Chem. C, 2007, 111, 13068-13075.

43 N. Kosinov and E. J. M. Hensen, in Nanotechnology in Catalysis, Wiley-VCH Verlag GmbH \& Co. KGaA, Weinheim, Germany, 2017, pp. 469-482. 
44 C. L. Garcia and J. A. Lercher, J. Phys. Chem., 1992, 96, 2669-2675.

45 F. Thibault-Starzyk, A. Vimont and J. P. Gilson, Stud. Surf. Sci. Catal., 2001, 135, 133.

46 G. Mirth and J. A. Lercher, J. Catal., 1991, 132, 244-252.

47 H. G. Karge, W. Nießen and H. Bludau, Appl. Catal. A Gen., 1996, 146, 339-349.

48 A. Vimont, O. Marie, J. P. Gilson, J. Saussey, F. Thibault-Starzyk and J. C. Lavalley, Catal. Deactiv. 1999, 1999, 126, 147-154.

49 S. Kim, T. J. Evans, C. Mukarakate, L. Bu, G. T. Beckham, M. R. Nimlos, R. S. Paton and D. J. Robichaud, ACS Sustain. Chem. Eng., 2016, 4, 2615-2623.

50 M. B. J. Roeffaers, B. F. Sels, H. Uji-i, B. Blanpain, P. L’hoëst, P. A. Jacobs, F. C. De Schryver, J. Hofkens and D. E. De Vos, Angew. Chemie - Int. Ed., 2007, 46, 1706-1709.

51 Z. Ristanović, M. M. Kerssens, A. V. Kubarev, F. C. Hendriks, P. Dedecker, J. Hofkens, M. B. J. Roeffaers and B. M. Weckhuysen, Angew. Chemie - Int. Ed., 2015, 54, 1836-1840. 